\title{
Identification of genes involved in serum tolerance in the clinical strain Cronobacter sakazakii ES5
}

Sarah Schwizer, Taurai Tasara, Katrin Zurfluh, Roger Stephan and Angelika Lehner*

\begin{abstract}
Background: Cronobacter spp. are opportunistic pathogens that can cause septicemia and infections of the central nervous system primarily in premature, low-birth weight and/or immune-compromised neonates. Serum resistance is a crucial virulence factor for the development of systemic infections, including bacteremia. It was the aim of the current study to identify genes involved in serum tolerance in a selected Cronobacter sakazakii strain of clinical origin.
\end{abstract}

Results: Screening of 2749 random transposon knock out mutants of a C. sakazakii ES 5 library for modified serum tolerance (compared to wild type) revealed 10 mutants showing significantly increased/reduced resistance to serum killing. Identification of the affected sites in mutants displaying reduced serum resistance revealed genes encoding for surface and membrane proteins as well as regulatory elements or chaperones. By this approach, the involvement of the yet undescribed Wzy_C superfamily domain containing coding region in serum tolerance was observed and experimentally confirmed. Additionally, knock out mutants with enhanced serum tolerance were observed. Examination of respective transposon insertion loci revealed regulatory (repressor) elements, coding regions for chaperones and efflux systems as well as the coding region for the protein YbaJ. Real time expression analysis experiments revealed, that knock out of the gene for this protein negatively affects the expression of the fimA gene, which is a key structural component of the formation of fimbriae. Fimbriae are structures of high immunogenic potential and it is likely that absence/truncation of the ybaJ gene resulted in a non-fimbriated phenotype accounting for the enhanced survival of this mutant in human serum.

Conclusion: By using a transposon knock out approach we were able to identify genes involved in both increased and reduced serum tolerance in Cronobacter sakazakii ES5. This study reveals first insights in the complex nature of serum tolerance of Cronobacter spp.

Keywords: Cronobacter sakazakii ES5, Clinical isolate, Serum tolerance, Tn5-mutagenesis, Identification, PCR, Complementation, Expression analysis

\section{Background}

The genus Cronobacter, member of the family Enterobacteriaceae, comprises seven species - C. sakazakii, $C$. turicensis, C. malonaticus, C. muytjensii, C. dublinensis, C. universalis and C. condimenti [1,2]. They are opportunistic pathogens that can cause septicaemia and infections of the central nervous system primarily in premature, low-birth weight and/or immune-compromised neonates [3]. Most

\footnotetext{
* Correspondence: lehnera@fsafety.uzh.ch

Institute for Food Safety and Hygiene, Vetsuisse Faculty, University of Zurich, Zurich, Switzerland
}

\section{() Biomed Central

(C) 2013 Schwizer et al.; licensee BioMed Central Ltd. This is an Open Access article distributed under the terms of the Creative Commons Attribution License (http://creativecommons.org/licenses/by/2.0), which permits unrestricted use, distribution, and reproduction in any medium, provided the original work is properly cited. outbreaks have been reported in neonatal intensive care units where the sources of infection have been traced to Cronobacter spp. contaminated, reconstituted powdered infant formula (PIF) and/or feeding equipment.

As a foodborne pathogen causing systemic infections, Cronobacter spp. must cross the gastrointestinal barrier and, following their tropism for the central nervous system, translocate to and cross the blood-brain barrier (BBB). In that context, it is expected that Cronobacter spp. express virulence factors that help in colonization and invasion of mucosal cells [4] as well as effectors that confer the ability of Cronobacter spp. to overcome the mechanisms of killing 
by serum components and/or the human complement system $[5,6]$.

Microbes that cause invasive infections have evolved strategies to protect themselves against the bactericidal action of the serum/complement. Structures of the bacterial cell surface, such as capsules, LPS and outer-membrane proteins have been identified as being responsible for the complement resistance of bacteria [6,7]. For Cronobacter spp. it has been shown, that the outer membrane protein Omp A contributes significantly to the survival of the bacteria in the blood [8].

In a more recent study an outer membrane protease Cpa has been identified as a factor that activates plasminogen, thus mediating serum resistance in C. sakazakii [9]. However, it has been demonstrated, that there is a considerable degree of variation among Cronobacter spp. isolates with respect to their ability to resist serum complement [10]. In a pilot study a set of Cronobacter isolates (all species, subspecies) from various origins (clinical, environment, milk powder) was tested for their capacity to survive in human blood and the clinical isolate Cronobacter sakazakii ES5 was identified as the most tolerant strain (i.e. $\leq 2 \log$ reduction during incubation in 50\% human pooled serum for $120 \mathrm{~min}$ ) among the Cronobacter sakazakii isolates tested (data not shown).

This strain was selected for further experiments aiming for the identification and analysis of genes involved in this feature.

\section{Results and discussion}

Identification of genes involved in modified serum tolerance in C. sakazakii

Screening of 2749 random mutants from a C. sakazakii ES5 Tn5 library for modified serum tolerance revealed 10 candidates for which a significantly increased/reduced tolerance to serum killing (as compared to the wild type) was confirmed. In Figure 1 the variations in the survival of the mutants expressed as log variation (y-axis) over time (x-axis) is depicted. Serum sensitivity was expressed in $\log$ variations (number of $\mathrm{cfu} \mathrm{ml}^{-1}$ after incubation in $50 \%$ human pooled serum (HPS) for 60 and $120 \mathrm{~min}$

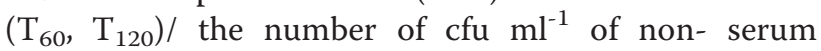
exposed inoculum $\left(\mathrm{T}_{0}\right)$. By referring the counts after incubation to $\mathrm{T}_{0}$, the inoculum variations were corrected for all experiments.

Only mutants for which a single transposon insertion in the chromosome was confirmed were subjected to the subsequent mapping experiments. The sequences obtained were subjected to similarity searches at the NCBI website.

Table 1 summarizes the affected coding regions for the mutants, the closest homologue on the amino acid level and description of the putative function of the protein.

Identification of the respective mutated sites from mutants displaying reduced serum resistance included

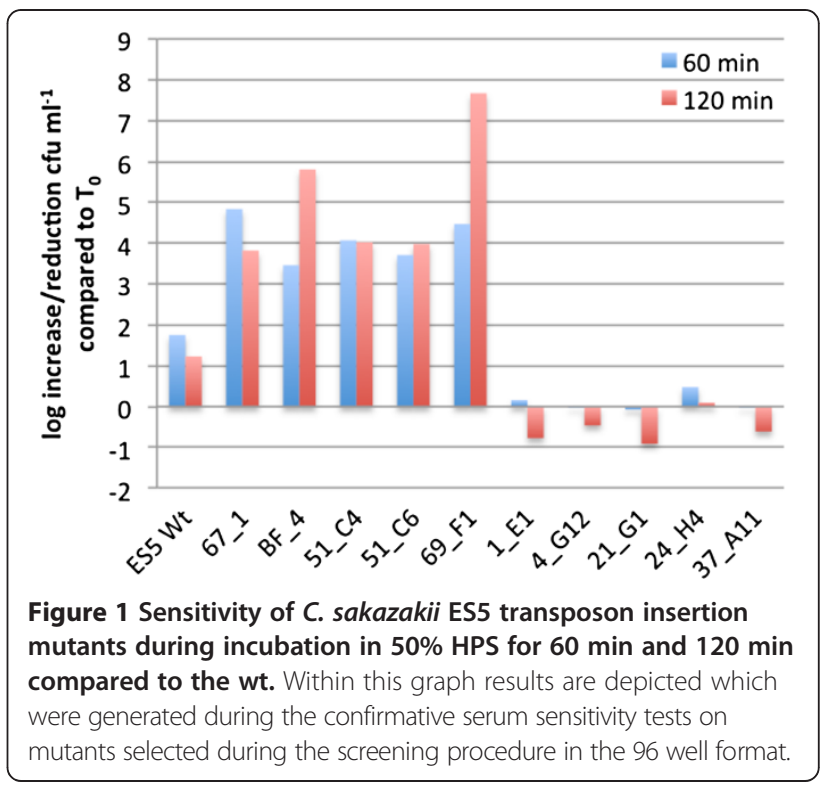

genes coding for surface and membrane proteins (67.1, BF4), (transcription) regulatory genes (51_C4, 51_C6) as well as a DnaJ domain containing protein (69_F1). Mutant 67_1 represents a knock out in the igaA coding gene. This non-pigmented mutant has been identified in the study by Johler et al. (2012) but was not subject of further investigation in this study [11]. However, this protein was identified in Salmonella Typhimurium as a membrane protein that attenuates the response of the RcsCDB signalling system to environmental stress. The Rcs two component system is known to be involved in the (positive/negative) regulation of a number of target genes including biofilm formation and pathogenicity. Thus, it has been reported, that the constitutive activation of this system dramatically attenuates Salmonella virulence [12].

Mutant BF4 was originally described in the study by Hartmann et al. (2010) where it was found to produce less biofilm on polystyrene [13]. The transposon insertion affected a site with 100\% homology to the locus ESA_04103 of the C. sakazakii ATCC BAA 894 genome (CP000783.1) to which the annotation hypothetical protein was available at that time. However, BLASTx analysis of the respective protein reveals homology to proteins containing a conserved Wzy_C superfamily domain. The coding region for this protein must not be confused with the gene for the Wzy protein which is part of the O- antigen gene locus (often referred to as $r f b$ locus in Enterobacteriaceae) located between ESA_01177 and ESA_01190 the function of which is annotated as $\mathrm{O}$-antigen polymerase. The O-antigen forms part of the lipopolysaccharide (LPS) in the outer membrane of Gram-negative bacteria and is one of the most variable constituents on the cell surface. There are 
Table 1 Identification and description of affected insertion sites in mutants displaying modified serum resistance in C. sakazakii ES5

\begin{tabular}{|c|c|c|c|c|}
\hline \multirow[b]{2}{*}{ Mutant } & \multicolumn{4}{|l|}{ Annotation } \\
\hline & Phenotype & $\begin{array}{l}\text { Locus tag closest } \\
\text { homologue blastx/organism }\end{array}$ & $\begin{array}{l}\text { Protein Name } \\
\text { (max ident aa) }\end{array}$ & Description \\
\hline $67.1^{\mathrm{a}}$ & $\begin{array}{l}\text { Reduced serum } \\
\text { resistance }\end{array}$ & $\begin{array}{l}\text { ESA_04343/Cronobacter } \\
\text { sakazakii BAA-894 }\end{array}$ & $\begin{array}{l}\text { Putative uncharacterized } \\
\text { protein }(100 \%)\end{array}$ & $\begin{array}{l}\text { Putative membrane protein IgaA homolog } \\
\text { (C. turicensis z3032) }\end{array}$ \\
\hline$B F 4^{b}$ & $\begin{array}{l}\text { Reduced serum } \\
\text { resistance }\end{array}$ & $\begin{array}{l}\text { ESA_04103/Cronobacter } \\
\text { sakazakii BAA-894 }\end{array}$ & $\begin{array}{l}\text { Putative uncharacterized } \\
\text { protein }(100 \%)\end{array}$ & $\begin{array}{l}\text { Hypothetical protein, conserved domain: Wzy_C } \\
\text { superfamily O-antigene ligase }\end{array}$ \\
\hline $51 \_C 4^{c}$ & $\begin{array}{l}\text { Reduced serum } \\
\text { resistance }\end{array}$ & $\begin{array}{l}\text { ESA_03258/Cronobacter } \\
\text { sakazakiiBAA-894 }\end{array}$ & $\begin{array}{l}\text { DNA binding transcriptional } \\
\text { regulator FruR (99\%) }\end{array}$ & Fructose repressor \\
\hline $51+C 6^{c}$ & $\begin{array}{l}\text { Reduced serum } \\
\text { resistance }\end{array}$ & $\begin{array}{l}\text { CSE899_07155/Cronobacter } \\
\text { sakazakii E899 }\end{array}$ & Hypothetical protein (100\%) & $\begin{array}{l}\text { FadR, GNTR family of transcriptional regulator, winged } \\
\text { helix-turn helix DNA binding domain. }\end{array}$ \\
\hline $69 F^{c}$ & $\begin{array}{l}\text { Reduced serum } \\
\text { resistance }\end{array}$ & $\begin{array}{l}\text { ESA_01368 Cronobacter } \\
\text { sakazakii BAA-894 }\end{array}$ & Hypothetical protein (98\%) & DnaJ domain protein \\
\hline $1 \_E 1^{c}$ & $\begin{array}{l}\text { Increased serum } \\
\text { resistance }\end{array}$ & $\begin{array}{l}\text { CSE899_13864 Cronobacter } \\
\text { sakazakii E899 }\end{array}$ & $\begin{array}{l}\text { Copper homeostasis protein } \\
\text { CutC }(100 \%)\end{array}$ & Uncharacterized protein involved in copper resistance \\
\hline 4_G12 & $\begin{array}{l}\text { Increased serum } \\
\text { resistance }\end{array}$ & $\begin{array}{l}\text { ESA_03283 Cronobacter } \\
\text { sakazakii ATCC BAA-894 }\end{array}$ & Hypothetical protein (99\%) & DjlA \\
\hline $21+G 1^{c}$ & $\begin{array}{l}\text { Increased serum } \\
\text { resistance }\end{array}$ & $\begin{array}{l}\text { ESA_02809/Cronobacter } \\
\text { sakazakii BAA-894 }\end{array}$ & Hypothetical protein (99\%) & $\begin{array}{l}\text { Hha toxicity attenuator, YbaJ "biofilm formation regulator" } \\
\text { C. sakazakii E899 }\end{array}$ \\
\hline 24_H4 $4^{\mathrm{C}}$ & $\begin{array}{l}\text { Increased serum } \\
\text { resistance }\end{array}$ & $\begin{array}{l}\text { ESA_03832/Cronobacter } \\
\text { sakazakii BAA-894 }\end{array}$ & Hypothetical protein (100\%) & ribonuclease activity regulator protein RraA \\
\hline $37 \_\mathrm{A} 11^{\mathrm{C}}$ & $\begin{array}{l}\text { Increased serum } \\
\text { resistance }\end{array}$ & $\begin{array}{l}\text { Ctu_3p00270/Cronobacter } \\
\text { turicensis z3032 }\end{array}$ & Hypothetical protein (99\%) & $\begin{array}{l}\text { On Plasmid pCtu3 of C. turicensis z3032 - no annotation } \\
\text { available }\end{array}$ \\
\hline
\end{tabular}

a obtained from the study by Johler et al., 2010 [11].

b obtained from the study by Hartmann et al., 2010 [13].

c this study.

currently seven (O1-O7) different O-antigen serotypes described for $C$. sakazakii and the putative organization of the genes included in the different clusters has been published recently $[14,15]$. As in one of these serotypes (O7), the wzy gene does not seem to be part of the cluster it has been proposed, that a different, yet unknown gene mapping elsewhere in the chromosome may code for this essential function and we further hypothesized that the ESA_04103 coding region may have been a candidate for this. However, determination of the O-antigen serotype of the C. sakazakii ES5 strain by application of a recently developed PCR based serotyping scheme [16] revealed that this strain belongs to the $\mathrm{O} 2$ serotype (data not shown).

As to date there is no experimental data on the involvement of the ESA_04103 coding region in serum tolerance available, we aimed to investigate whether an intact copy of the ESA_04103 gene provided in trans to the ESA_04103 deleted mutant BF4 would restore the serum tolerance to wild type level. Therefore this gene including its putative native promoter region was cloned onto a low copy expression vector and the resulting construct was transformed into BF4 mutant. Serum sensitivity tests were performed using the $C$. sakazakii ES5 wt strain, the BF4

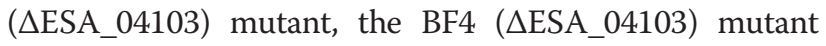
containing an empty pCCR9 vector (BF4_pCCR9) and the complemented mutant BF4_pCCR9::ESA_04103. The results of these experiments are depicted in Figure 2. An inactivation around 5 log during incubation in $50 \%$ human serum for $120 \mathrm{~min}$ was observed in the BF4 ( $\triangle \mathrm{ESA}$ _04103) mutant as well as the mutant containing the low copy vector pCCR9, whereas the survival of the mutant with supplied vector pCCR9 and ESA_04103 was restored to $4 \log$ reduction $\mathrm{cfu} \mathrm{m} \mathrm{m}^{-1}$ compared to $\mathrm{T}_{0}$ compared to the wt with $1.2 \log$ reduction. We could, however, not completely restore the serum survival to wild type levels in the complemented mutant. This may be explained (in part) by the unknown copy number of the mRNA for this gene in the wild type during incubation in serum and/or by possible polar effects.

Mutant 69_F1 was identified to be affected in a gene coding for a DnaJ domain family protein. Members of this family are essential for their interaction with DnaK chaperone and activation of its ATPase activity. In Edwardsiella tarda it was recently demonstrated that DnaJ and DnaK play a crucial role in general bacterial virulence, in blood dissemination capacity [16].

Interestingly, by using the Tn5 approach we found an equally high number of knock out mutants, that showed an enhanced survival in human serum compared to the wild type. One of the obvious possibilities to explain this phenomenon would be the knock out of regulatory 


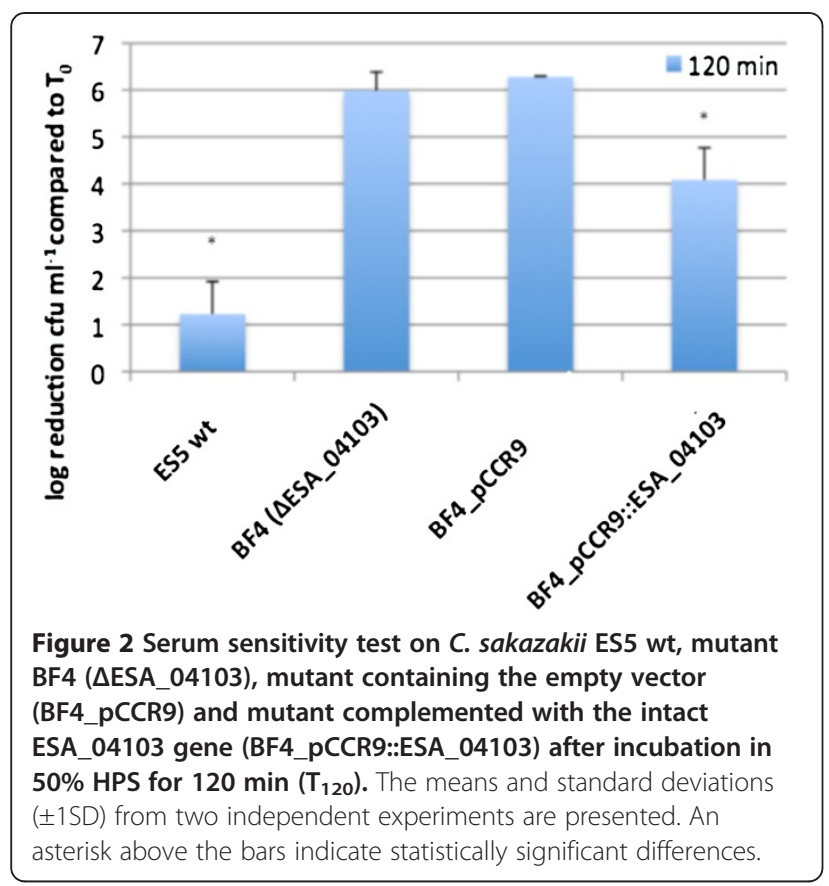

elements (repressors) which would lead to a subsequent activation/constitutive expression of the respective phenotype. Mutant 24_H4 ( $\triangle r r a A)$ may fall into this category. The region affected by the transposon in this mutant shows homology to the ribonuclease regulator protein RraA. This protein acts as an inhibitor of the essential endoribonuclease RNase E, which itself plays a crucial role in global mRNA metabolism as well as in the maturation of functional RNAs such as rRNAs, tRNAs, tmRNA, and small regulatory RNAs [17-20]. However, Lee et al. [21] demonstrated that ectopic expression of RraA itself affects the abundance of more than 700 transcripts in Escherichia coli, thus making it difficult to hypothesize upon the influence of the knock out of this gene on the enhanced survival of the mutant in human serum.

More surprising was the finding that deletions in genes putatively coding for (co-)chaperones lead to an enhanced survival in human serum. One of those, namely 4_G12 $(\triangle d j l A)$, is a member of the J-domain protein family. DjlA can substitute for DnaJ co-chaperone [22] and seems to have multiple functions. However, it has also been described that DjlA negatively regulates the response of the two component RcsCDB signaling system to envelope stress. The Rcs signal transduction system positively regulates the expression of many different genes among those are the ones forming the capsular polysaccharide synthesis operon (cps) [23]. The expression of capsules may provide protection from serum killing components (see above). In a study by Shiba et al. [24] it was demonstrated that djlA deletion resulted in increased activation of the Rcs system. This might positively regulate cps transcription.

Mutant 21_G1 ( $\Delta y b a J)$ exhibiting an enhanced serum tolerance was shown to be affected in a gene coding for the YbaJ protein. It has been proposed that $\mathrm{YbaJ}$ and its adjacent protein Hha may form a so called toxin-antitoxin pair where YbaJ (antitoxin) negatively regulates the expression of Hha (toxin), the latter one (among other functions) serving as a repressor for type 1 fimbriae [25]. Type 1 fimbriae are highly immunogenic, thus a strain not expressing these structures may have an advantage in survival during exposure in human serum [26].

In the present study we further examined the hypothesis that the disruption of the regulatory gene $y b a J$ may lead to an activation of the Hha protein which in turn would negatively influence transcription of the key fimbrial structural gene fimA. RT-qPCR experiments were performed in order to quantify hha and fimA mRNA levels in the $C$. sakazakii ES5 wt and mutant 21_G1( $\Delta y b a J)$ strains, before and after exposure to human serum. The levels of fimA mRNA were more than $4.5 \log$ lower in the mutant 21_G1( $(y b a J)$ strain compared to the C. sakazakii ES5 wt strain. The hha mRNA levels were for the mutant compared to the wt $5 \mathrm{log}$ lower and not like expected higher, suggesting that the deletion of the $y b a J$ gene did not result directly in a de-repression/ activation of the hha gene in our experimental set up (Figure 3). Our results rather suggest that $y b a J$ itself may be involved in the regulation/activation of the expression of the type 1 fimbriae in C. sakazakii.

\section{Conclusions}

By using a transposon knock out approach we were able to identify structural and regulatory genes in Cronobacter sakazakii ES5, deletion of which resulted in a dramatically reduced capability to survive in serum. Additionally, several mutants were found displaying an enhanced survival in serum as compared to the wild type. Analysis of the genetic elements possibly responsible for this phenotype revealed genes coding for chaperone-like proteins, regulatory (repressor) elements as well as genes for structures or components representing immunogenic targets. The deletion of the $y b a J$ element which is part of the antitoxin-toxin pair YbaJ-Hha resulted in an abolished expression of a key element of the type 1 fimbriae. The absence of the latter most likely accounted for the enhanced survival of this mutant in human serum.

\section{Methods}

\section{Bacterial strains and culture conditions}

Cronobacter sakazakii strain E5, a clinical strain was used in this study. Wild type and mutant strains, E. coli DH5 alpha as well as plasmids and primers that were included and constructed during the transposon library 

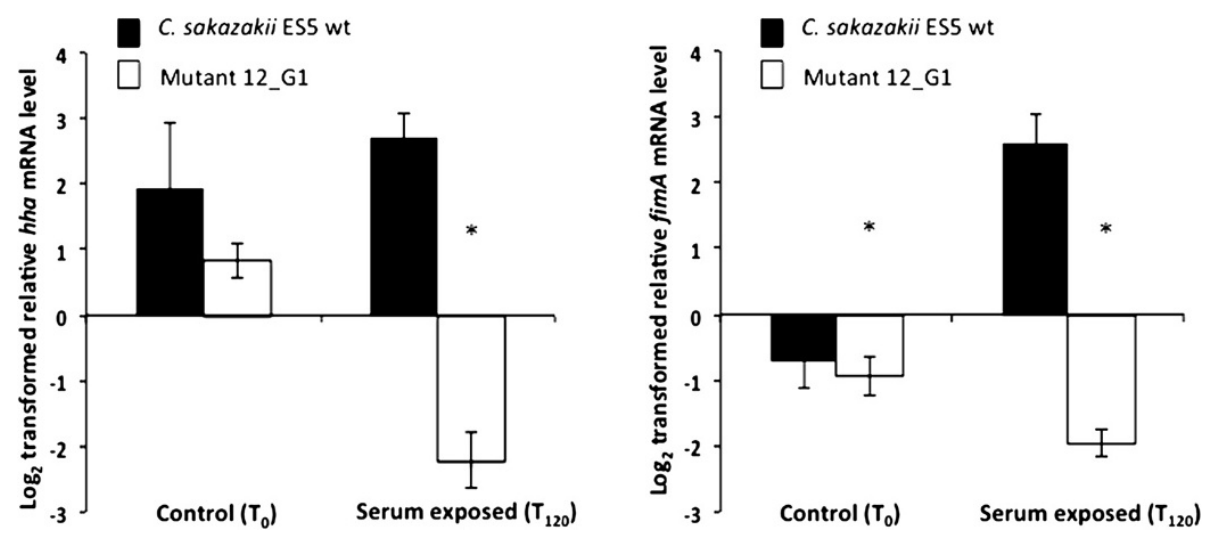

Figure 3 Relative levels of $h$ ha and fimA mRNA in control $\left(\mathrm{T}_{0}\right)$ and serum treated $\left(\mathrm{T}_{120}\right)$ C. sakazakii ES5 wt and mutant 21_G1 ( $\Delta y b a$ ) cells. RNA was isolated from mid exponential growth stage cells prior $\left(T_{0}\right)$ and after $\left(T_{120}\right)$ human serum exposure. Values were normalized using $16 \mathrm{~S}$ rRNA as a reference gene. The means and standard deviations $( \pm 1 S D)$ from three independent experiments are presented. An asterisk above the bars indicate statistically significant differences in mRNA levels between the C. sakazakii ES5 wt and mutant $(P<0.05)$.

screening, the mutant complementation (BF4) and the expression (21_G1) experiments are summarized in Table 2. All strains were incubated at $37^{\circ} \mathrm{C}$ in Luria-Bertani (LB) broth, over night with gentle shaking. When appropriate, antibiotics were used at the following concentrations: kanamycin at $50 \mu \mathrm{g} \mathrm{ml}^{-1}$ and tetracyclin at $50 \mu \mathrm{g} \mathrm{ml} \mathrm{m}^{-1}$.

\section{Identifcation of transposon mutants modulating serum tolerance in Cronobacter sakazakii ES 5}

A random transposon mutant (EZ-Tn5 $<\mathrm{KAN}-2>\mathrm{Tnp})$ library of the clinical isolate Cronobacter sakazakii ES5 $[11,13]$ was screened for modified (i.e. significant log variation in survival during exposure compared to wild type) survival in 50\% human pooled serum (HPS) over a period of $120 \mathrm{~min}$. For these experiments, the mutants were grown in 96 well microtiterplates overnight in LB supplemented with $50 \mu \mathrm{g} / \mathrm{ml}$ kanamycin at $37^{\circ} \mathrm{C}$. Ten $\mu \mathrm{l}$ of these overnight cultures were transferred into a 96 well screening plate containing $50 \mu \mathrm{l} \mathrm{HPS}$ and $40 \mu \mathrm{l} 0.9 \% \mathrm{NaCl}$ per well and incubated for $120 \mathrm{~min}$ at $37^{\circ} \mathrm{C}\left(\mathrm{T}_{120}\right)$. Concentrations of bacterial cultures were determined by $\mathrm{OD}_{590 \mathrm{~nm}}$ measurement at $\mathrm{T}_{0}$ and $\mathrm{T}_{120}$ and compared to respective wild type measurements. Thresholds of (1) more than 2 times reduction and (2) more than 7 times increase of OD value during incubation for $120 \mathrm{~min}$ relative to the wild type values were set in order to identify potential candidates which were subsequently subjected to a confirming serum sensitivity test.

\section{Confirmative serum sensitivity tests}

LB grown overnight cultures were diluted $1: 20$ in $10 \mathrm{ml}$ $\mathrm{LB}$ and allowed to grow at $37^{\circ} \mathrm{C}$ to $\mathrm{OD}_{590 \mathrm{~nm}}=0.5$. Cells were washed twice in $0.9 \% \mathrm{NaCl}$, resuspended in $5 \mathrm{ml}$ $0.9 \% \mathrm{NaCl}$ and diluted to $10^{-2}$. These dilutions $\left(=10^{0}\right)$ served as inoculum for the experiments in $50 \%$ human serum. Concentrations of bacterial inoculations at $\mathrm{T}_{0}$ were determined by plating $100 \mathrm{ul}$ of $10^{-3}, 10^{-4}$ and $10^{-5}$ dilutions of the inoculum on LB plates and enumeration of CFU after incubation at $37^{\circ} \mathrm{C}$ overnight. Two hundred fifty $\mu \mathrm{l}$ HPS was mixed with $50 \mu \mathrm{l}$ of the above

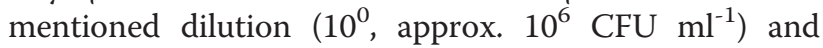
$200 \mu \mathrm{l}$ of $0.9 \% \mathrm{NaCl}$ and incubated at $37^{\circ} \mathrm{C}$. Survival of the bacterial cells during incubation in 50\% HPS was followed by plate count enumeration (plating of $100 \mathrm{ul}$ of a dilution series $10^{-1}-10^{-5}$ ) after 60 and $120 \mathrm{~min}$ $\left(\mathrm{T}_{60}, \mathrm{~T}_{120}\right)$. Sensitivity during exposure was expressed in $\log$ reduction rates as number of bacteria that survived treatment/number of bacteria in non - serum- exposed inoculum $=\mathrm{T}_{0}$ ). The activity of the human pooled serum (HPS) used for the experiments was tested by comparing cfu $\mathrm{ml}^{-1}$ determined after incubation of C. sakazakii E5 strain in $50 \%$ native or heat inactivated $\left(56^{\circ} \mathrm{C}\right.$ for $30 \mathrm{~min}$ ) HPS for $120 \mathrm{~min}$ for each new batch (batch control, data not shown).

During serum sensitivity tests on (pCCR9 vector containing) mutants BF4_pCCR9 and BF4_pCCR9:: ESA_04103, the serum as well as the plate count medium for enumeration was supplemented with kanamycin and tetracycline both at $50 \mu \mathrm{g} \mathrm{ml}$.

\section{Identification of transposon insertion sites}

All kits for DNA isolation and purification were obtained from Qiagen (Hilden, Germany) and handled by following the manufacturer's instructions. Unless otherwise stated, chromosomal DNA was isolated using the DNeasy Blood and Tissue kit. Plasmids were extracted with the QIAprep Spin Miniprep or Plasmid Midi kits. DNA fragments from PCRs, restriction digests, and agarose gels were purified using the MinElute PCR Cleanup kit and the MinElute Gel Purification kit, respectively. The concentration of nucleic acids was determined using a Nanodrop ND-1000 
Table 2 Material used in this study

\begin{tabular}{|c|c|c|}
\hline Strains/plasmids/primers & Genotype/characteristic(s)/sequences & Source or reference \\
\hline \multicolumn{3}{|l|}{ Strains } \\
\hline \multicolumn{3}{|l|}{ Cronobacter sakazakii } \\
\hline ES5 (wild type) & Human isolate & Hartmann et al., 2010, Johler et al., 2010 [11,13] \\
\hline BF4 (mutant) & $\Delta$ ESA_04103, Kan ${ }^{R}$ & Hartmann et al., 2010 [13] \\
\hline BF4_pCCR9 & BF4 harboring pCCR9, $\operatorname{Kan}^{R}$, Tet $^{R}$ & This study \\
\hline BF4_pCCR9::ESA_04103 & BF4 harboring pCCR9:: ESA_04103, Kann $^{R}$, Tet $^{R}$ & This study \\
\hline 21_G1 (mutant) & $\Delta y b a J, \operatorname{Kan}^{R}$ & This study \\
\hline Escherichia coli DH5 alpha & $\begin{array}{l}\text { F- } \Phi \text { 80lacZuM15 } \Delta \text { (lacZYA-argF) U169 recA1 endA1 hsdR17 } \\
\text { (rK-, mK+) phoA supE44 } \lambda \text { - thi-1 gyrA96 relA1 }\end{array}$ & Epicentre \\
\hline \multicolumn{3}{|l|}{ Plasmids } \\
\hline pUC19 & High copy cloning/expression vector $A m p^{R}$ & Epicentre \\
\hline pCCR9 & Low copy cloning/expression vector, Tet $^{R}$ & Randegger et al., 2000 [28] \\
\hline pCCR9::ESA_04103 & pCCR9::ESA_04103, Tet ${ }^{R}$ & This study \\
\hline \multicolumn{3}{|l|}{ Primer for sequencing } \\
\hline KAN-2FP1 & $5^{\prime}$-ACC TAC AAC AAA GCT CTCATC AAC C-3' & Epicentre \\
\hline pCCR9-F & $5^{\prime}-T \Pi T$ GAC AGC TTA TCA TCG-3 & This study \\
\hline pCCR9-R & 5'-CCT ATG GAA GTT GAT CAG-3 & This study \\
\hline \multicolumn{3}{|l|}{ Primer for complementation } \\
\hline $\mathrm{BF} 4 \mathrm{f}^{1}$ & 5'-GAC GCC AAG CTT GCG CGA GCC TGC GTT TAA-3' & This study \\
\hline $\mathrm{BF} 4 \mathrm{r}^{2}$ & 5'- AGT CTG GGA TCC AAA CAT TAT CCT TCT TTA TAG-3' & This study \\
\hline \multicolumn{3}{|l|}{ Target/primer for expression } \\
\hline ybaJf & 5'-CGG CAT GAT ATA GCG CAG-3' & This study \\
\hline ybaJr & 5'-GAT GTG TAT AAG AGA CAG-3' & This study \\
\hline hhaf & $5^{\prime}$-CAA ACC ATT AAC CAA AAC CG-3' & This study \\
\hline hhar & 5'-CGG AAT TाT ATC GTA GAG CTT-3' & This study \\
\hline fimAf & 5'-AAA CCG CGT TTA CTG G-3' & This study \\
\hline fimAr & $5^{\prime}$-GCA ACG GAG TIT GCT T-3' & This study \\
\hline $16 \mathrm{~S}$ rRNAf & $5^{\prime}$-GTG TTG TGA AAT GTT GGG T-3' & This study \\
\hline $16 \mathrm{~S}$ rRNAr & $5^{\prime}$-ACT AGC GAT TCC GAC TT-3' & This study \\
\hline
\end{tabular}

${ }^{1}$ Primer sequence is underlined, recognition site for restriction enzyme Hind III is given in bold.

2 Primer sequence is underlined, recognition site for restriction enzyme Bam $\mathrm{HI}$ is given in bold.

UV/Vis spectrophotometer (NanoDrop Technologies, Wilmington, DE). Mutants with confirmed phenotype were further subjected to Southern blot analysis in order to determine the chromosomal transposon copy number [11]. Only mutants for which a transposon copy number of one was confirmed were subject of further analysis. Mapping of transposon insertion sites using a subcloning approach was performed as described previously [11]. In brief, chromosomal DNA of the transposon mutants was digested with SphI. The fragments were ligated into pUC19 (Table 2) digested with the same enzyme. After ligation $\left(12 \mathrm{~h}\right.$ at $\left.16^{\circ} \mathrm{C}\right)$ the construct was electroporated into $E$. coli DH5 alpha (Table 2). Transformants carrying a plasmid containing the transposon (= kanamycin cassette) were identified by plating the transformants on LB supplemented with kanamycin. Plasmids were extracted from the selected clones, and the transposon-flanking regions were sequenced with primer KAN-2 FP1 (Table 2). Transposon insertion sites were determined by sequencing the junctions between the Tn5 transposon sites and the ES5 chromosomal DNA. All sequencing was outsourced (Microsynth, Balgach, Switzerland). The sequences obtained from each mutant were determined by similarity search using BLASTn and BLASTx at the NCBI website http://blast.ncbi.nlm.nih.gov/Blast.cgi [27]. The original nucleotide sequences obtained for the mutants after sequencing are provided as supplementary data (Additional file 1).

The cloning, restriction enzyme analysis, and transformation of C. sakazakii were performed using standard 
techniques. Enzymes and respective buffers were obtained from Roche (Basel, Switzerland) or New England Biolabs (Ipswich, MA).

\section{Complementation experiment with serum sensitive mutant and BF4 (DESA_04103)}

The ESA_04103 locus was amplified using primer pair BF4f and BF4r (Table 2). This primer pair was designed based on the whole genome sequence of Cronobacter sakazakii BAA-894 (CP000783.1) spanning the region from 4058124 to 4059648 , including the putative coding sequence as well as $220 \mathrm{bp}$ upstream of the open reading frame in order to ensure the inclusion of the native promoter. The amplification mix contained $0.4 \mu \mathrm{M}$ of primers, 1 x AccuPrime (Invitrogen) buffer $2(60 \mathrm{mM}$ Tris- $\mathrm{SO}_{4}$ (pH 8.9), $18 \mathrm{mM}\left(\mathrm{NH}_{4}\right)_{2} \mathrm{SO}_{4}, 2 \mathrm{mM} \mathrm{MgSO}$, $2 \mathrm{mM}$ dGTP, $0.2 \mathrm{mM}$ dATP, $0.2 \mathrm{mM}$ dTTP, $0.2 \mathrm{mM}$ dCTP, thermostable AccuPrimeTM protein, 1\% glycerol) and $2 \mathrm{U}$ AccuPrime Taq DNA Polymerase High Fidelity (Invitrogen). Following PCR conditions were used: $94^{\circ} \mathrm{C}$ for $30 \mathrm{~s}$ followed by 35 cycles of $94^{\circ} \mathrm{C}$ for $30 \mathrm{~s}, 54^{\circ} \mathrm{C}$ for $30 \mathrm{~s}$ and $68^{\circ} \mathrm{C}$ for $120 \mathrm{~s}$.

The resulting PCR products were double digested with the restriction enzymes Hind $\mathrm{III}$ and $\mathrm{Bam} \mathrm{HI}$ and cloned into the low copy vector pCCR9 [28] which had been digested with the respective enzymes to create the complementation vector pCCR9::ESA_04103. The construct was transformed into the BF4 mutant strain by electroporation and transformants were selected on LB agar supplemented with kanamycin and tetracycline. The correct insertion of the desired fragment was confirmed by amplification and sequencing of the insert of a complemented BF4 mutant using primers located on the pCCR9 vector (pCCR9-F and pCCR9-R, Table 2) and employing the conditions as described during the complementation cloning approach. The sequence of the insert is provided in Additional file 1. Additionally a BF4 mutant containing the pCCR9 vector (BF4_pCCR9) only (no insert) was created and used together with the complemented strain BF4_pCCR9:: ESA_04103 in the serum sensitivity assay as described above. The serum assays were carried out in duplicates (= two independent experiments).

\section{Serum exposure and RNA purification}

An $0.5 \mathrm{ml}$ aliquot of a stationary phase grown culture of the wt and mutant strain was used to inoculate $10 \mathrm{ml}$ of LB and grown to the mid exponential growth stage $\left(\mathrm{OD}_{590 \mathrm{~nm}}=0.5\right)$ at $37^{\circ} \mathrm{C}$. Cronobacter cells were washed twice in $10 \mathrm{ml}$ and finally resuspended in $5 \mathrm{ml}$ of $0.9 \%$ $\mathrm{NaCl}$ solution. Two and half milliliters of the resuspended Cronobacter cells were mixed with $12.5 \mathrm{ml} \mathrm{HPS}$ and $10 \mathrm{ml}$ $0.9 \% \mathrm{NaCl}$. Aliquots of $10 \mathrm{ml}$ were promptly collected. The mixtures were incubated for 120 minutes at $37^{\circ} \mathrm{C}$ and a second set of aliquots was collected. RNA profiles in collected aliquots were promptly preserved using the bacterial RNA Protect Reagent (Qiagen). Cronobacter cell pellets were immediately processed or frozen at $-70^{\circ} \mathrm{C}$ for total RNA extraction at a later stage. Total RNA was isolated using the Qiagen RNeasy Plus Mini kit (Qiagen) with minor modifications to the original kit protocol. Cronobacter cells resuspended in $0.5 \mathrm{ml}$ RNeasy Plus Mini Kit lysis buffer (Qiagen) were transferred on to the lysing bead matrix in MagNA lyser tubes and mechanically disrupted in the MagNA Lyser Instrument (Roche Molecular Diagnostics). Two DNA removal steps were incorporated by using a genomic DNA binding column included in the RNeasy Plus Mini Kit as well as by performing an in-column DNAseI (RNase-Free DNase; Qiagen) digestion of the samples bound to the RNA spin column. Total RNA was eluted from the column into $30 \mu \mathrm{l}$ of RNAse-free water. RNA yields were determined using the Nanodrop ND-1000 spectrophotometer (Nano Drop Technologies, Wilmington, DE). RNA quality was assessed using the Agilent 2100 Bioanalyzer (Agilent Technologies, Santa Clara, CA, USA). Purified RNA was immediately frozen $-70^{\circ} \mathrm{C}$ for long-term storage.

\section{DNA synthesis and quantitative real time PCR}

The synthesis of cDNA was performed using the Quantitect Reverse Transcription Kit (Qiagen). One microgram of total RNA was reverse transcribed to cDNA in $20 \mu \mathrm{l}$. Generated cDNA was amplified by quantitative real-time PCR using the Light Cycler 480 instrument (Roche Molecular Diagnostics, Rotkreuz, Switzerland). Primers used for the amplification of the target ( $h h a$ and fimA) and reference (16S rRNA) genes are listed in Table 2. Primers were designed using the LC probe design software (Roche Molecular Diagnostics, Penzburg, Germany). Quantitative real-time PCR mixtures contained Light Cycler R 480 SYBR Green I Master $(5 \mu \mathrm{l})$, forward and reverse primer mixture $(2.5 \mu \mathrm{l})$ and $100 \mathrm{ng}$ of the cDNA template $(2.5 \mu \mathrm{l})$. The PCR cycling conditions were as previously described [29]. Reference gene validation was performed as previously described [30], and this established that $16 \mathrm{~S}$ rRNA mRNA levels were suitable for normalization of relative mRNA quantification under experimental conditions of the present study. The hha and fimA mRNA levels were quantified relative to the $16 \mathrm{~S}$ rRNA reference gene and the Light Cycler 480 Relative Quantification Software (Roche Molecular Diagnostics). The relative hha and fimA mRNA levels obtained after normalization were log converted and data shown are based on the means and standard deviations from three independent assays. The statistical significance of differences in hha and fimA mRNA levels between Cronobacter wt and mutant strains were analyzed using t-tests, 
and P-values $<0.05$ were considered to be statistically significant.

\section{Additional file}

Additional file 1: A: Results of the sequencing of the transposon insertion flanking sites of the mutants identified in this study, B: Sequence of the ESA_04103 insert after amplification of the pCCR9:: ESA_04103 complemented BF4 mutant.

\section{Competing interests}

The authors declare that they have no competing interests.

\section{Authors' contributions}

SS carried out the majority of the experiments, KZ helped during the molecular work. AL and TT conceived the study design, coordinated the molecular work and helped to draft the manuscript. TT contributed to the interpretation of the RT PCR data. RS participated in the design of the study and helped to draft the manuscript. All authors read and approved the final manuscript.

Received: 26 October 2012 Accepted: 14 February 2013

Published: 15 February 2013

\section{References}

1. Iversen C, Mullane N, McCardell B, Tall BD, Lehner A, Fanning S, Stephan R, Joosten $\mathrm{H}$ : Cronobacter gen. nov., a new genus to accommodate the biogroups of Enterobacter sakazakii, and proposal of Cronobacter sakazakii gen. nov. comb. nov., C. malonaticus sp. nov., C. turicensis sp. nov., C. muytjensii sp. nov., C. dublinensis sp. nov., Cronobacter genomospecies 1 , and of three subspecies, C. dublinensis sp. nov. subsp. dublinensis subsp. nov., C. dublinensis sp. nov. subsp. lausannensis subsp. nov., and C. dublinensis sp. nov. subsp. lactaridi subsp. nov. Int I Syst Evol Microbiol 2008, 58:1442-1447.

2. Joseph S, Cetinkaya E, Drahovska H, Levican A, Figueras MJ, Forsythe SJ: Cronobacter condimenti sp. nov., isolated from spiced meat, and Cronobacter universalis sp. nov., a species designation for Cronobacter sp. genomospecies 1, recovered from a leg infection, water and food ingredients. Int J Syst Evol Microbiol 2012, 62:1277-1283.

3. Bowen $A B$, Braden CR: Invasive Enterobacter disease in infants. Emerg Infect Dis 2006, 12:1185-1189.

4. Mange JP, Stephan R, Borel N, Wol d P, Kim KS, Pospischil A, Lehner A: Adhesive propertries of Enterobacter sakazakii to numan epithelial and brain microvascular endothelial cells. BMC Microbio/ 2006, 6:58.

5. Joiner KA: Complement evasion by bacteria and parasites. Annu Rev Microbiol 1988, 42:201-230.

6. Taylor PW: Bactericidal and bacteriolytic activity of serum against gramnegative bacteria. Microbiol Rev 1983, 47:4683.

7. Rautemaa R, Meri S: Complement-resistance mechanisms of bacteria. Microb Infect 1999, 1:785-794.

8. Mittal R, Wang Y, Hunter CJ, Gonzalez-Gomez I, Prasadarao N: Brain damage in newborn rat model of meningitis by Enterobacter sazakazii: a role for outer membrane protein A. Lab Invest 2009, 89:263-277.

9. Franco AA, Kothary MH, Gopinath $G$, Jarvis KG, Grim CJ, Hu L, Datta AR, McCardell BA, Tall BD: Cpa, the outer membrane protease of Cronobacter sakazakii, activates plasminogen and mediates resistance to serum bactericidal activity. Infect Immunol 2011, 79:1578-1587.

10. Townsend SM, Hurrell E, Gonzalez-Gomez I, Lowe J, Frye JG, Forsythe S, Badger JL: Enterobacter sakazakii invades brain capillary endothelial cells, persists in human macrophages influencing cytokine secretion and induces severe brain pathology in the neonatal rat. Microbio/ 2007, 153:3538-3547.

11. Johler S, Stephan R, Hartmann I, Kuehner KA, Lehner A: Yellow pigmentation in Cronobacter sakazakii ES5: genes involved and influence on persistence and growth under environmental stress. Appl Environ Microbiol 2010, 76:1053-1061.

12. Mouslim C, Delgado M, Groisman EA: Activation of the RcsC YojN/RcsB phophorelay system attenuates Salmonella virulence. Mol Microbiol 2004, 54:386-395.
13. Hartmann I, Carranza P, Lehner A, Stephan R, Eberl L, Riedel K: Genes involved in Cronobacter sakazakii biofilm formation. Appl Environ Microbiol 2010, 76:2251-2261.

14. Sun Y, Wang M, Liu H, Wang J, He X, Zheng J, Guo X, Cao B, Wang L: Development of an O-antigen serotyping scheme for Cronobacter sakazakii. Appl Environ Microbiol 2011, 77:2209-2214.

15. Sun Y, Wang M, Wang Q, Cao B, Zhe X, Li K, Feng L, Wang L: Genetic analysis of the Cronobacter sakazakii $\mathrm{O} 4$ to $\mathrm{O} 7 \mathrm{O}$-antigen gene clusters and Development of a PCR assay for identification of all C. sakazakii O serotypes. Appl Environ Microbiol 2012, 78:3966-3974.

16. Dang W, Zhang M, Sun L: Edwardsiella tarda DnaJ is a virulenceassociated molecular chaperone with immunoprotective potential. Fish Shellfish Immun 2011, 31:182-188.

17. Ghora BK, Apirion D: Structural analysis and in vitro processing to $\mathrm{p} 5$ rRNA of a 9S RNA molecule isolated from an rne mutant of $E$. coli. Cell 1978, 15:1055-1066.

18. Li Z, Deutscher MP: RNase E plays an essential role in the maturation of Escherichia coli tRNA precursors. RNA 2002, 8:97-109.

19. Li Z, Pandit S, Deutscher MP: RNase G (CafA protein) and RNase E are both required for the 5/ maturation of $16 \mathrm{~S}$ ribosomal RNA. EMBO J 1999 18:2878-2885.

20. Ow M, Kushner SR: Initiation of tRNA maturation by RNase $E$ is essential for cell viability in E. coli. Genes Dev 2002, 16:1102-1115.

21. Lee K, Zhan X, Gao J, Qiu J, Feng Y, Meganathan R, Cohen SN, Georgiou G: RraA, a protein inhibitor of RNase E activity that globally modulates RNA abundance in E. coli. Cell 2003, 114:623-634.

22. Genevaux P, Wawrzynow A, Zylicz M, Georgopoulos C, Kelley WL: DjIA is a third DnaK co-chaperone of Escherichia coli, and DjIA-mediated induction of colanic acid capsule requires DjlA-DnaK interaction. J Biol Chem 2001, 276:7906-7912.

23. Majdalanim N, Gottesman S: The Rcs phosphorelay: a complex signal transduction system. Annu Rev Microbiol 2005, 59:379-405.

24. Shiba Y, Matsumoto K, Hara H: DjlA negatively regulates the Rcs signal transduction system in Escherichia coli. Genes Genetic System 2006, 81:51-56.

25. Garcia-Contreras R, Zhang XS, Kim Y, Wood TK: Protein translation and cell death: the role of rare tRNAs in biofilm formation and in activating dormant phage killer genes. PLoS One 2008, 3:2394.

26. Klemm P, Schembri MA: Fimbral surface display systems in bacteria: from vaccines to random libraries. Microbiology 2000, 146:3025-3032.

27. National Center for biotechnology Information. http://blast.ncbi.nlm.nih.gov/ Blast.cgi.

28. Randegger CC, Keller A, Irla M, Wada A, Hächler H: Contribution of natural amino acid substitutions in SHV extended-spectrum beta-lactamases to resistance against various betalactams. Antimicrob Agents Chemother 2000, 44:2759-2763.

29. Arguedas-Villa C, Stephan R, Tasara T: Evaluation of cold growth and related gene transcription responses associated with Listeria monocytogenes strains of different origins. Food Microbiol 2010, 27:653-660.

30. Tasara T, Stephan R: Evaluation of housekeeping genes in Listeria monocytogenes as potential internal control references for normalizing mRNA expression levels in stress adaptation models using real-time PCR. FEMS Microbiol Lett 2007, 269:265-272.

doi:10.1186/1471-2180-13-38

Cite this article as: Schwizer et al:: Identification of genes involved in serum tolerance in the clinical strain Cronobacter sakazakii ES5. BMC Microbiology 2013 13:38. 